\title{
Impact of anxiety and life stress upon eyewitness testimony
}

\author{
JUDI'TH M. SIEGEL and ELIZABETH F. LOFTUS \\ University of Washington, Seattle, Washington 98195
}

\begin{abstract}
Eighty-four subjects participated in a study designed to explore the relationship between the psychological state of a witness and the witness's ability to accurately perceive and recall a complex incident. It was found that persons who are anxious and preoccupied, as measured by standard tests, performed more poorly on a test measuring eyewitness accuracy.
\end{abstract}

In France's (1909) Penguin Island, there is a chapter about "the dragon of Alca." It is about a frightful dragon who was supposedly ravaging the Penguin people, a group of peaceful people who ordinarily inhabited Alca in perfect tranquility. One day, the elders of the village assembled in a public place to query the villagers about the dragon. One said, "He has the claws of a lion, the wings of an eagle, and the tail of a serpent." Another said, "He has the head of a dragon, the claws of a lion, and the tail of a fish." One said he was red, another green, another blue, another yellow, and yet another, "His colour? He has no colour."

Although obviously fiction, France's story illustrates an important fact. When people witness a complex event, their recollections differ. No two people will give the identical account. Thus, it is important from both a practical and a theoretical point of view to determine those factors that best predict an individual's ability to perceive and recall complex information accurately.

Past research has looked at such witness factors as age, sex, education, intelligence, and training, but there has been little investigation of the role that anxiety and life stress play upon the ability of an eyewitness to perceive and recall accurately. There are several lines of research that suggest that these factors relate to eyewitness ability. Easterbrook (1959) showed that increased emotional arousal is associated with a reduction in the range of task-relevant cues to which an individual attends. Thus, the highly aroused individual may be prevented from encoding important information about a stimulus event. Sarason (1975) suggested that not only does the anxious individual attend to fewer task-relevant cues, but he or she may also become preoccupied with internal cues, such as concerns about performance or worries about other problems. It was hypothesized, therefore, that higher scores on

This research was supported in part by grants from the National Institute of Mental Health and the National Science Foundation to E. Loftus, and in part by a grant from the Office of Naval Research to I. Sarason. Requests for reprints should be sent to Judith Siegel, Community Health Care Systems, University of Washington, Seattle, Washington 98195. personality measures of anxiety would be associated with lower scores on a test of eyewitness ability.

In a legal proceeding, one may wish to analyze particular eyewitnesses with an eye toward determining which witnesses are likely to report accurately. Should a connection between anxiety and eyewitness ability be observed, this factor could be used to screen witnesses. On the other hand, it is not easy to determine how anxious a given individual is; this must be done by administering a standardized test. It would be desirable to have a way of tapping anxiety indirectly, without actually testing the witness, for all too often such testing is impossible. A measure of the witness's recent life changes may provide this indirect measure. Several studies have suggested that the accumulation of undesirable life changes, or life stress, is associated with psychological problems such as anxiety and depression (Dohrenwend \& Dohrenwend, 1972; Sarason, Johnson, \& Siegel, in press; Vinokur \& Selzer, 1975). It might be expected, then, that life stress would also be negatively related to performance on a test of eyewitness ability. The present study was aimed at determining the interrelationship among these variables.

\section{METHOD}

Eighty-four undergraduate students enrolled in introductory psychology courses participated in this study. Subjects were run in groups of three to five, and they were told that the purpose of the experiment was to assess their performance on cognitive tasks.

During the experimental session, each subject completed a self-report measure of anxiety, an eyewitness testimony task, and a scale designed to measure self-preoccupation. The anxiety measure, the Multiple Affect Adjective Checklist (MAACL) (Zuckerman \& Lubin, 1965), consists of a list of 132 mood adjectives (e.g., agitated, calm, desperate). Subjects respond by endorsing the adjectives that are descriptive of the way they feel at the time the test is administered. Twenty-one of the adjectives are relevant for the scoring of the anxiety subscale of the MAACL.

The eyewitness testimony task was designed to measure the subject's ability to perceive and recall a complex event. The subjects were shown a sequence of 24 slides, at a 5 -sec rate, depicting a wallet-snatching incident in a small town. The sequence opens with a young woman walking down a busy street. She meets a friend and stops to talk for a moment. As 
the woman continues down the street, she is approached by a man wearing a cowboy hat who bumps into her, causing her to drop her shopping bag. The man and woman both stoop to pick up some articles that have fallen out. When the woman is looking the other way, the man reaches into her shoulder bag and takes her red wallet. The woman does not notice and the two part. Soon, the victim becomes aware that her wallet is missing, at which point two other women cross the street toward her and gesture in the direction of the fleeing man.

After viewing the slides, the subjects spent about $1 \mathrm{~min}$ clearing their desks and writing their names on all of their booklets. Then, they filled out a questionnaire designed to determine accuracy. The questionnaire consisted of 30 items that addressed diverse details of the wallet-snatching incident. It asked about major details, such as information about the central characters, their clothing, and their actions, and it asked about minor details, such as the surrounding environment, extraneous people, buildings, and traffic. The 30 items were declarative sentences requiring a phrase or word to be completed. To complete these sentences, a five-alternative multiple-choice test was given. For example, one question was, "The thief wore a (a) heavy shirt, (b) long winter coat, (c) short winter coat, (d) light jacket, (e) down vest."

The self-preoccupation scale (Sarason \& Stoops, 1978) measures the degree to which an individual is preoccupied by task-irrelevant thoughts. The scale yields two scores: Scale 1 consists of the subjects' responses to items dealing specifically with fears about performance (e.g., I thought about how poorly I was doing); Scale 2 consists of the subjects' judgments concerning how much their minds wandered during the preceding task.

In addition to the measures completed during the experimental session, scores on the Life Experiences Survey (LES) (Sarason et al., in press), a measure of life stress, were also available for each subject. The LES is a 57-item self-report inventory to which subjects respond by endorsing those events they have experienced in the past year (e.g., death of a close friend, marriage, new job). Respondents rate both the desirability (positive or negative) of each event they have experienced and the magnitude of the impact (0 to 3 ). The inventory is scored by summing the impact ratings for those events rated as undesirable by the respondent. Previous research has suggested that undesirable life changes are consistently related to psychological problems (Sarason et al., in press; Vinokur \& Selzer, 1975), not to change per se, as suggested by earlier work (cf. Holmes \& Rahe, 1967).

\section{RESULTS}

The mean correct on the 30-item eyewitness accuracy test was 14.58 . The mean score on the anxiety scale of the MAACL was 7.67. Subjects scored an average of 24.19 on Scale 1 of the preoccupation measure and 2.83 on the item assessing how much their minds wandered during the task (scored on a 7-point scale).

Of central interest in the present research was the relationship between eyewitness ability and the other individual measures. Pearson product-moment correlations were computed between performance on the eyewitness task and the measures of anxiety, preoccupation, and life stress. As predicted, performance on the test of eyewitness ability was negatively correlated with anxiety $[\mathrm{r}(84)=-.20, \mathrm{p}<.05]$, with preoccupation Scale $1[\mathrm{r}(84)=-.24, \mathrm{p}<.01]$, and with preoccupation Scale $2[r(84)=-.26, p<.01]$. Although the results for life stress were suggestive, the correlation was not statistically significant $[\mathrm{r}(84)=-.12, \mathrm{p}<.13]$. Thus, the results indicate that persons who are more anxious and preoccupied tend to perform more poorly on a test of eyewitness ability.

\section{DISCUSSION}

The results of this study suggest that eyewitness ability is affected by the psychological state of the witness. Specifically, anxiety and preoccupation seem to result in less efficient performance. As suggested by both Easterbrook (1959) and Sarason (1975), the highly anxious individual may not be vigilant to important task-relevant cues, and thus may miss some of the information that is crucial for the eyewitness task.

While these findings are useful for future laboratory studies of eyewitness ability, the important question is the degree to which this information can be integrated into the courtroom setting. The data provide some tentative evidence that recent life stresses may contribute to inaccurate eyewitness testimony. Although this finding is only suggestive, it is likely that there are other variables that moderate this relationship. For example, Smith, Johnson, and Sarason (1978) have found that the accumulation of life stress exerts a detrimental impact primarily on individuals who try to minimize their level of stimulation, or low-sensation seekers (Zuckerman, Kolin, Price, \& Zoob, 1964). It is the task of future research to refine our knowledge concerning those individual difference variables that contribute to eyewitness accuracy and to provide the avenues for employing this information in the courtroom setting.

\section{REFERENCES}

Dohrenwend, B. S., \& Dohrenwend, B. P. Stressful life events. New York: Wiley, 1974.

EASTERBROOK, J. A. The effect of emotion on cue utilization and the organization of behavior. Psychology Review, 1959, 66, 183-201.

France, A. Penguin island. New York: Dodd, Mead, 1909.

Holmes, T. H., \& RAHE, R. H. The social readjustment rating scale. Journal of Psychosomatic Research, 1967, 11, 213-218.

SARAson, I. G. Anxiety and self-preoccupation. In I. G. Sarason \& C. D. Spielberger (Ed.), Anxiety: Current trends in theory and research (Vol. 2). New York: Wiley (Halsted), 1975.

Sarason, I. G., Johnson, J. H., \& Siegel, J. M. Assessing the impact of life change: The development of the Life Experiences Survey. Journal of Consulting and Clinical Psychology, in press.

Sarason, I. G., \& Stoops, R. Test anxiety and the passage of time. Journal of Consulting and Clinical Psychology, 1978, 46, 102-109.

Smith, R. E., Johnson, J. H., \& Sarason, I. G. Life change, the sensation seeking motive, and psychological distress. Journal of Consulting and Clinical Psychology, 1978, 46, 348-349.

Vinokur, A., \& Selzer, M. L. Desirable versus undesirable life events: Their relationship to stress and mental distress. Journal of Personality and Social Psychology, 1975, 32, 329-337.

Zuckerman, M., Kolin, E. A., Price, L., \& Zoob, I. Development of a sensation seeking scale. Journal of Consulting Psychology, 1964, 26, 250-260.

ZuCKERMAN, M., \& LUBIN, B. Manual for the multiple affect adjective checklist. San Diego, Calif: Educational and Industrial Testing Service, 1965.

(Received for publication August 18, 1978.) 